\title{
Dificuldades da aprendizagem do sistema decimal francês de numeração: remediações baseadas na filosofia da linguagem de Wittgenstein
}

Learning difficulties of the French decimal numbering system: remediations based on Wittgenstein's philosophy of language

Marie Esther Charles ${ }^{1}$

\section{Resumo}

O objetivo deste estudo consiste em relacionar os jogos de linguagem de Wittgenstein como ferramenta para a compreensão dos meandros das linguagens envolvidas no ensino do sistema de numeração (língua francesa e linguagem matemática) para crianças do nível primário. As investigações realizadas sobre o ensino da numeração e nossa experiência no ensino da matemática nos deram pistas sobre as dificuldades potenciais das crianças. Além disso, estudos já realizados por Ballieu et al. (2004), Tempier (2013), Ribière (2006) etc. informam que os erros dos alunos em numeração decimal vêm principalmente do código verbal de certos números que não correspondem ao código escrito. Assim, para superar essas dificuldades, trabalhamos com os conceitos de jogo da linguagem e seguir as regras, temas muito relevantes da segunda filosofia de Wittgenstein, nos mostraram diretrizes para ajudar a fornecer algumas orientações.

Palavras-chave: Linguagem matemática. Jogo de linguagem. Seguir regras. Filosofia de Wittgenstein.

\section{Abstract}

The aim of this study is to relate Wittgenstein's language games as a tool for understanding the intricacies of the languages involved in teaching the numbering system (French language and mathematical language) for primary school children. Research into numbering teaching and our experience in mathematics teaching has given us clues about the potential difficulties of children. In addition, studies already performed by Ballieu et al. (2004), Tempier (2013), Ribière (2006), etc. report that student errors in decimal numbering come mainly from the verbal code of certain numbers that do not correspond to the written code. Thus, to overcome these difficulties, we worked with the concepts of language play and following the rules, very relevant themes of Wittgenstein's second philosophy, showed us guidelines to help provide some guidance.

Keywords: Mathematical language. Language game. Follow rules. Wittgenstein's philosophy.

\footnotetext{
${ }^{1}$ Mestranda do Programa de Pós-Graduação em Educação em Ciências e Matemáticas da Universidade Federal do Pará - chesther10@yahoo.fr
}

BoEM, Joinville, v. 7, n. 14, p. 94-112, dez 2019 
http://dx.doi.org/10.5965/2357724X07142019094

\section{Introdução}

É quase impraticável ensinar o sistema de numeração decimal sem ter a bagagem linguística em conformidade com o campo de estudo ensinado e sem uma formação prévia. Cada área de estudo tem uma linguagem própria e precisa ser aplicada segundo as regras gramaticais que a elaboram. O papel duplo da língua como vetor e objeto das aprendizagens disciplinares faz dela um instrumento essencial e todos os que se empenham no ramo da educação deveriam promover ações visando em primeiro lugar dominá-la.

Assim, as questões linguísticas são hoje objeto de numerosos estudos no ensino da matemática, dada a importância atribuída à língua neste domínio. A matemática, por seu lado, disciplina dotada de uma linguagem especializada merece ser levada em conta desde a entrada da criança na escola, a fim de desenvolver as suas competências desde a mais tenra idade, começando por fixar as bases da aprendizagem dos números por via oral e escrita. Assim, como todos os ramos matemáticos apelam primeiro ao conhecimento dos números, torna-se primordial ensinar bem às crianças as técnicas de contagem, o que constituirá o ponto de partida para qualquer aquisição da linguagem numérica.

Ballieu et al. (2004) sublinham que de acordo com os testemunhos dos etnólogos e os achados arqueológicos, desde a antiguidade, o homem sempre teve necessidade de contar, entretanto, não podemos atribuir a este ato uma origem exata. Muitas técnicas de contagem foram utilizadas antes da adoção da que utilizamos no presente momento: a contagem decimal.

O sistema de numeração decimal francês apresenta uma estrutura sintática, cuja denominação oral se distingue da escrita, o que gera obstáculos na aprendizagem dos números, e dependendo da língua de ensino, as dificuldades no início da escola primária podem revelar-se mais comprometedoras numa língua do que em outras.

Assim, o ensino de um sistema de algoritmos que não leva em consideração as dificuldades das crianças e o uso de uma linguagem inapropriada aumentam a incompreensão dos alunos sobre a numeração e fazem parte das principais razões do 
fracasso dessas crianças em matemática. A aprendizagem dos números deveria ser o objeto de um ensino centrado na implantação das primeiras regras para facilitar a compreensão das noções da linguagem matemática, que acompanharão a criança ao longo do seu percurso escolar.

Dessa forma, levar o aluno a compreender os códigos verbal e oral da numeração decimal reside na implantação de um jogo de linguagem que lhe permita dominar e se apropriar da linguagem matemática. O conceito de "jogo de linguagem", descrito por Wittgenstein nas Investigações Filosóficas (1999), é uma maneira de conceber o ensino de forma diferente para facilitar o aprendizado, associa-o aos diferentes usos que podem ser feitos de uma palavra de acordo com um contexto específico. Nesse sentido, segundo o autor, "a expressão jogo de linguagem deve aqui salientar que o falar uma língua é uma parte de uma atividade ou de uma forma de vida" (WITTGENSTEIN, 1999, p. 35). Então, o objetivo deste estudo consiste em relacionar os jogos de linguagem de Wittgenstein como ferramenta para a compreensão dos meandros das linguagens envolvidas no ensino do sistema de numeração (língua francesa e linguagem matemática) para crianças do nível primário.

Para melhor compreensão do texto, vamos focar em primeiro lugar na estrutura dos números ao longo do ciclo primário, em seguida, localizar as áreas de dificuldade das crianças em contagem e finalmente, propor uma estrutura de mediação inspirada na segunda filosofia de Wittgenstein.

\section{Estrutura da numeração decimal}

Fayol, citado por Ribière (2006, p. 6) define a numeração como um "sistema organizado, elaborado e implementado no seio de uma dada cultura. Trata-se de um produto sócio histórico exterior à criança, mas que deve apropriar-se e interiorizar para resolver os problemas com que se vê confrontado" (tradução livre).

Como um produto sócio histórico, os números que utilizamos nos nossos dias percorreram um longo caminho e constituíram uma fonte de dificuldades para os povos primitivos. Ballieu et al. (2004) nos informam do tempo do aparecimento dos primeiros símbolos digitais, época em que os homens usavam bolsas cheias de pedras, entalhes 
em ossos ou em madeira para contar os rebanhos de ovelhas na Mesopotâmia. Mesmo assim, eles não deixaram de construir um sistema que lhe permitisse escrever e reter os números. Em seguida, apareceram os sistemas de contagem egípcio, chinês, grego, maia, romano, etc. até chegar ao sistema atual. Para fazer isso, o homem trabalhou sua inteligência a fim de desenvolver um sistema de escrita de números que satisfizesse suas necessidades, caso contrário, de que modo procederia para efetuar a partilha das terras, dos recursos, dos rendimentos, efetuar trocas comerciais?

Esses diferentes sistemas de numeração desenvolvidos pelo homem ao longo da história mostram a sua criatividade e conduziram à adoção quase universal do sistema que hoje utilizamos: o sistema decimal, de origem indo-arábica, segundo Moretti (1999), que sofreu várias modificações antes da adoção dos símbolos que hoje utilizamos e que apresenta as seguintes características: sua base é 10; usa dez sinais diferentes que são chamados de algarismos e estes são: $0,1,2,3,4,5,6,7,8,9$; utiliza o princípio da notação posicional, porque é a posição que determina o valor que os algarismos deverão assumir; utiliza o zero para substituir a ausência de uma dezena, centena, etc. Pode-se dizer que o zero é indispensável para interpretar corretamente um número neste caso. Este sistema se assenta também nos princípios multiplicativo e aditivo.

Para falar do sistema decimal indo-arábico, convém sobretudo analisar os aspectos da sua estrutura que nos permitirão depois adotar uma abordagem quanto à forma como ensiná-la. Como a numeração decimal é formada por regras e por uma linguagem que Ihe são próprias, devem ser tidas em conta no início da escola fundamental, a fim de facilitar a aprendizagem ao longo de todo o ciclo primário.

Os sistemas falados e escritos da numeração decimal são construídos "de forma progressiva a partir dos dez primeiros números e do seu nome no sistema falado. As unidades de numeração (unidades, dezenas, centenas...) desempenham um papel essencial na ligação entre estes dois sistemas" (TEMPIER, 2013, p. 21) e segundo Houdement e Chambris citados por Tempier (2013, p. 23), "as unidades de número permitem fazer uma ponte entre os sistemas de contagem falado e escrito". A construção dos números é iterativa pelo fato de os saberes em numeração serem definidos por números inteiros até 9 numa primeira fase, de 10 a 99, numa segunda fase e assim por 
diante. Isto funciona de modo que "os saberes definidos para uma unidade se baseiam nos saberes definidos pela unidade inferior" (TEMPIER, 2013, p.22), isto significa que, por esta construção, temos a vantagem de adquirir novos conhecimentos em cada etapa da aprendizagem dos números.

Na escrita, os primeiros nove números são: $1,2,3,4,5,6,7,8,9$ e no oral escrevem-se da seguinte forma: um, dois, três, quatro, cinco, seis, sete, oito, nove. Estes números representam unidades simples (ou unidades de primeira ordem) simbolizadas por "U" cuja escrita pode apresentar-se de acordo com o seguinte exemplo: 5 unidades ou 5 - cinco unidades ou cinco. $\mathrm{E}$, quando não se especifica a unidade utilizada, tratase de fato da unidade simples. Nós podemos dizer que esta estrutura dos números é a mesma em todos os países que usam estes sinais do sistema da numeração decimal.

O número 10 inicia a formação dos números de dois dígitos, e para construí-lo, utiliza-se a unidade exatamente anterior acrescentada de uma unidade. Assim, 9 unidades + 1 unidade dá 10 que é apenas uma dezena simbolizada por "D" e que representa dez unidades. Nosso sistema de numeração escrito é posicional, com o aparecimento da dezena, a escrita é feita em linha, colocando cada unidade na fila que corresponde a ela, começando da direita para a esquerda. Então, uma dezena representa 10 unidades com esta notação $1 \mathrm{D}$, e colocada no quadro de numeração, teremos esta representação:

Tabela das unidades ${ }^{2}$

\begin{tabular}{|c|c|c|}
\hline Centena & Dezena & Unidade \\
\hline & 1 & 0 \\
\hline
\end{tabular}

Como mencionamos anteriormente, nosso sistema de numeração escrito usa o número zero para marcar a ausência, assim duas dezenas se escreve 20, três dezenas se escreve 30, ..., nove dezenas escreve-se 90. No entanto, segundo Tempier (2013), um número de dois dígitos só pode ter um zero na fila das unidades (simples).

2 Fonte: a autora

BoEM, Joinville, v. 7, n. 14, p. 94-112, dez 2019 
http://dx.doi.org/10.5965/2357724X07142019094

No sistema de numeração falado, existem zonas de irregularidades na construção de dezenas que apresentam mais dificuldades em certas línguas do que em outras. Neste caso, na língua francesa, traçam-se duas zonas de irregularidades que se situam nas faixas de 11 a 16 e de 70 a 99, mas a faixa de 20 a 69 apresenta uma regularidade. Neste sentido, "para ler um número, basta fazer a ligação entre o número de dezenas e o nome da parcela" (PINEL, 2015, p. 14), como em oito dezenas, escreve-se oitenta. Pinel (2015) sublinha também que, embora a parcela de "20"' seja regular, mas em francês, como também pudemos notar em português, é especial porque não se ouve o som "dois" da dezena nem a sua raiz quando se lê por exemplo "21, 22, 23,...". Enquanto para as dezenas seguintes, pode-se facilmente fazer a ligação entre o número de dezenas e o número com o qual é escrito, como no caso do "35", o som "tri" de trinta faz logo pensar no número 3.

$\mathrm{Na}$ construção das centenas que formas a faixa de 100 a 999, o sistema de designação oral dos números segue a seguinte regra e é regular: a leitura dos números é feita da esquerda para a direita dizendo o número de centenas, depois o número de dezenas e por último o das unidades, de onde se lê 435 (quatrocentos e trinta e cinco). Uma centena forma-se da seguinte maneira: $9 \mathrm{D} 9 \mathrm{U}+1 \mathrm{U}(99 \mathrm{U}+1 \mathrm{U})$ que dá uma nova unidade chamada "100" (ou unidade da terceira ordem). A centena é simbolicamente representada por "C" e, em termos de correspondência com as outras ordens, vale 100 unidades ou 10 dezenas.

No sistema escrito, Tempier (2013) informa-nos que se coloca as centenas na terceira fila a partir da direita por respeito ao princípio da posição. Então 1 centena escreve-se 100, 2 centenas escreve-se 200, .. 9 centenas escrevem-se 900, respeitando a escrita conforme o quadro de numeração da direita para a esquerda. No sistema falado, não há complicação, deve-se seguir o número de centenas da palavra cem, exceto para uma centena, onde é dito somente "cem" e não "um cem".

Tabela das unidades ${ }^{3}$

3 Fonte: a autora

BoEM, Joinville, v. 7, n. 14, p. 94-112, dez 2019 


\begin{tabular}{|c|c|c|}
\hline Centena & Dezena & Unidade \\
\hline 1 & 0 & 0 \\
\hline
\end{tabular}

Para a formação do milhar, procede-se deste modo $999 \mathrm{U}+1 \mathrm{U}$ (ou seja, $99 \mathrm{D}+$ $9 U+1 U)$ ou $(9 C+9 D+9 U+1 U)$. No sistema escrito, os milhares escrevem-se na quarta fila e anotam-se "M" e em caso de ausência de unidade, da dezena, da centena se escreve zero na carreira correspondente, então 1 milhar escreve-se 1000, 2 milhares escreve-se 2000, ... 9 milhares 9000. A escritura canônica dos números permite, segundo Tempier (2013, p. 27) "passar diretamente à escritura em números escrevendo diretamente as unidades na primeira fila, as dezenas na segunda, as centenas no terceiro e milhares no quarto.". Por exemplo, 6287 escreve-se: 6 M 2 C 8 D 7 U."

O que acontece com os milhares é que: 9 milhares 9 centenas 9 dezenas 9 unidades $+1 \mathrm{u}$ (ou seja, 9999 unidades +1 unidade) forma uma nova unidade chamada dez milhares (ou unidade de quinta ordem). A partir daí há uma mudança no nome das unidades de contagem, conforme nos observa (TEMPIER, 2013), não há nenhum nome novo, apenas a formação de um nome composto a partir dos nomes antigos, tomando como nova unidade o mil, e é por isso que nos diz o autor que não se introduz uma escrita abreviada para além do milhar.

Seguindo o princípio da posição, temos no sistema escrito uma dúzia de milhares que se escreve na quinta fila a partir da direita até chegar à centena de milhares formada assim: $99999 \mathrm{u}+1 \mathrm{u}$ que se escreve 100 mil e que representa uma unidade de sexta ordem. É importante sublinhar todas as relações que se podem estabelecer a partir da dezena de milhares e a centena de milhares com as outras unidades:

- Uma dezena de milhares $=$ dez milhares $=$ cem centenas $=$ mil dezenas $=$ dez mil unidades

- Uma centena de milhares $=$ dez dezenas de milhares $=$ cem milhares $=$ mil centenas $=$ dez mil dezenas $=$ cem mil unidades.

Como se atingiu três dígitos com a classe dos milhares, deve-se passar para uma nova classe, porque "uma classe é um agrupamento de três ordens de unidades 
consecutivas que correspondem da direita para a esquerda, às unidades, dezenas, centenas da mesma unidade". (TEMPIER, 2013, p. 27). Assim, temos a formação de duas classes: a das unidades simples e a dos milhares. Para a formação de novas classes como a dos milhões, bilhões, trilhões ... segue a mesma lógica como no quadro abaixo:

Tabela de numeração ${ }^{4}$

\begin{tabular}{|l|l|l|l|l|l|}
\hline \multicolumn{3}{|c|}{ Milhares } & \multicolumn{3}{c|}{ Unidades } \\
\hline Centena & Dezena & Unidade & Centena & Dezena & Unidade \\
\hline
\end{tabular}

Tudo o que acabamos de traçar é apenas para mostrar os passos que existem na escrita dos números, a fim de ajudar a identificar as zonas de emboscada que poderão, mais tarde, causar problemas de aprendizagem. É a partir desta estrutura bem ensinada, que o professor conseguirá fazer seus alunos compreenderem os outros jogos de linguagem que permeiam o ensino desse conteúdo. $O$ aluno que domina bem o princípio da posição dos números, a mudança para formar uma nova ordem, as técnicas de conversão entre as diferentes unidades, não terão certamente qualquer problema para comparar, ordenar os números e conseguir-se-á mesmo efetuar exercícios muito complexos em pouco tempo. Tudo o que o professor precisa é estabelecer, inicialmente, as regras de acordo com os princípios da numeração decimal, utilizando um jogo de linguagem adequado que favoreça a compreensão da criança, que faça sentido para ela, pois, segundo Wittgenstein (1999), só se encontra significado de uma palavra na prática da linguagem.

\section{Dificuldades da aprendizagem do sistema de numeração decimal}

Dependendo da língua falada, as crianças enfrentam certas dificuldades de aprendizagem, como no caso da língua francesa, em que alguns números apresentam uma estrutura oral que não corresponde à estrutura escrita. Neste caso, é o jogo de linguagem que o professor usará governado pelas regras desta numeração que

${ }^{4}$ Fonte: Elaborado pela autora

BoEM, Joinville, v. 7, n. 14, p. 94-112, dez 2019 
facilitarão a aprendizagem. Como mencionado por Silveira (2015, p. 233), "a linguagem que o professor utiliza para explicar os conceitos matemáticos é standard, uma linguagem padrão com um vocabulário específico, palavras restritas ao domínio do campo da matemática". Dito isto, esta linguagem deve ser provida de significado para o aluno para que possa dominar desde o início da escola fundamental o vocabulário relativo ao ato de ler e escrever os números.

As possíveis dificuldades na matemática identificadas nos alunos estão relacionadas aos aspectos posicionais e decimais da contagem. Ao aprender a contar no início da escola primária, alguns alunos têm dificuldade em acompanhar o ritmo dos algoritmos porque na contagem oral até 100 , existem duas faixas de irregularidades em relação à contagem escrita (PINEL, 2015). A primeira situa-se ao nível dos números de 11 a 16, em francês, por não ser construídos oralmente como os outros números de dois dígitos, a combinação da dezena e da unidade, por exemplo, não se diz: "dez-um, dezdois..." como na contagem chinesa. Em português, esta faixa de irregularidade vai de 11 a 15. Todo este problema reside no fato de que a nossa contagem oral não é posicional, o que lemos não corresponde ao que escrevemos, e não escrevemos o que ouvimos em alguns casos.

A segunda irregularidade na oralidade dos números em francês situa-se na faixa de 70 a 99. Essas "dificuldades aparecem porque o algoritmo ajustado previamente não trabalha mais e por outro lado, porque os nomes das dezenas têm construções diferentes" (PINEL, 2015, p. 14). Isto explica o fato de que, na construção das dezenas anteriores $10,20,30, \ldots, 60$, apenas se lê um número de uma palavra: dez, vinte, trinta, ..., sessenta. No entanto, de 70 a 99, alguns números podem ter uma estrutura aditiva, como é o caso, por exemplo, do número 70 , em que na sequência oral se ouve o seguinte: "sessenta-dez"' $(60+10)$; o número 80 tem uma estrutura multiplicadora, a gente entende sucessivamente a fala dos números "quatro-vinte" (4 × 20); o número 94 tem a sua estrutura multiplicativa e aditiva ao mesmo tempo e ouve-se oralmente "quatrovinte-quatorze" $(4 \times 20+14)$.

Estes dois tipos de irregularidades podem levar as crianças a cometer erros de natureza lexical. "Os erros lexicais são erros de notação ou de leitura, relacionados com 
o espaço ocupado por um dígito" (RIBIĖRE, 2006, p. 22). Esses erros ocorrem porque a criança ainda não interiorizou completamente o vocabulário relativo aos itens lexicais e a sua escrita cifrada. E, em presença dos grandes números, esses erros são mais marcados. O autor toma o exemplo do número "4" que se lê "quatro" quando ocupa o lugar das unidades, centenas ou ainda milhares, mas que se lê quarenta quando ocupa o lugar de dezenas, e outro tipo de erro que ocorre quando por exemplo o aluno escreve "10 007" em lugar de dez mil e setenta.

Por outro lado, as dificuldades das crianças em contagem situam-se ao nível do aspecto decimal. Tempier (2013) evoca o fato de que a criança interpreta a escrita de um número de acordo com sua posição sem saber o valor exato dessa posição em termos de agrupamentos. De acordo com o autor, é crucial que a criança associe à partida 10 unidades a uma dezena, quando não compreende a passagem para a dezena, não conseguirá compreender a representação de um pacote de 10 unidades pelo número "1", e que 1 pode valer 10, 100, 1000. Como sublinha Fayol, citado por Ribière (2006, p. 12): "a necessidade de ter em conta a posição que corresponde a potências diferentes de 10 , torna mais obscura, mais complexa a usar".

Digamos que o que acontece quando a criança não tem qualquer noção das palavras centenas, dezenas, unidades, ela não vai conseguir estabelecer a correspondência entre essas diferentes unidades de numeração, isso implica de acordo com Deblois citado por Tempier (2013, p. 72) que: "para estes alunos, os números parecem ser utilizados como objetos ou como unidades, sem relação com as unidades de medida de quantidades que representam".

Estes tipos de erros são qualificados de sintáticos e correspondem ao que Ribière (2006) nos faz saber àqueles em que o aluno associa o que ouve ou lê de termo a termo, por exemplo, ele escreverá "dois mil e vinte" assim: 2100020 ou pode associar cada item verbal a um dígito, então escreverá mil trezentos e quatro desta maneira: 134 (mil e cem representam 1) ou pode escrever quatro mil e trinta e dois assim "432", porque a palavra "cem" está ausente. Esta situação corresponde à situação em que o aluno não compreende e não pode explicar a utilização do zero para indicar a ausência de agrupamentos ou de fileiras. É o que acontece quando a criança enfrenta um exercício 
ditado ou escrito em letras, uma vez que não compreende a passagem de uma dezena para uma nova unidade, escreve as fatias ou as filas segundo o que vê ou entende sem se preocupar com o número de algarismos que cada classe deve conter após a primeira classe ouvida.

Deblois, citado por Tempier (2013, p. 72) "insiste no fato de que outros alunos atribuem uma posição a cada dígito e zero é então considerado como um número que não representa nenhum de algo que é agrupado em outra parte", por exemplo, ser-lhesá mais fácil escrever "56 dezenas = 560" sem poder explicar porquê, ou se derem uma resposta é a partir da relação de base que têm de: 1 dez $=10$ unidades, que converte 56 dezenas em 5 centenas e 60 unidades, tudo isso especifica o autor, é porque faltam exercícios de conversão nos livros.

Os meus anos de experiência como professora primária me permitem dizer que os exercícios de conversão noutras unidades que facilitariam a tarefa são pouco utilizados e pouco disponíveis nos livros de matemática dos alunos do ensino fundamental (caso dos livros haitianos ${ }^{5}$ ) e os professores que diversificam os exercícios são aqueles que têm a possibilidade de assistir a seminários, formação sobre as novas exigências do ensino da matemática ao nível primário ou que utilizem outros livros didáticos mais adaptados.

Estes casos que acabamos de descrever estão na base das dificuldades de aprendizagem em numeração e podem apresentar mais obstáculos em certas crianças do que em outras, dependendo da língua de ensino, por isso, estas dificuldades merecem ser tidas em conta no início do jardim de infância. O objetivo de um ensino baseado no desenvolvimento da criança será utilizar um jogo de linguagem centrado na terapia linguística que nos propõe Wittgenstein através sua filosofia da linguagem ajudará no ato de ensinar visando segundo Santos (2008, p. 166) "a inserção da criança em outros jogos de linguagem". E, como Wittgenstein (1999, p. 30) deu aos jogos de linguagem esta especificação dizendo que eles são "como um conjunto da linguagem e das atividades com as quais é interligada", então, estes jogos devem ser regidos por

${ }^{5}$ Habitantes do Haiti

BoEM, Joinville, v. 7, n. 14, p. 94-112, dez 2019 
http://dx.doi.org/10.5965/2357724X07142019094

regras e é na prática do uso da linguagem que as crianças entenderão e poderão descobrir outros jogos de linguagem mais complexos.

\section{Para melhores técnicas de ensino da numeração decimal}

Tendo em conta os problemas que a implantação das primeiras bases em numeração, como os professores deverão proceder para atingir um nível de ensino que responda às lacunas dos alunos? As dificuldades de aprendizado de numeração que acabamos de traçar sugerem que o idioma francês pode dificultar o aprendizado de numeração, dependendo de como as regras são estabelecidas desde o início.

Para entender essas regras, o conceito de jogos de linguagem, conceito central da segunda filosofia de Wittgenstein e por meio do qual ele nos faz entender que o significado de uma palavra está em seu contexto de uso, é o instrumento ideal sobre o qual muita pesquisa foi feita para abordar questões educacionais e, ao mesmo tempo, fornece elementos de resposta. É verdade que Wittgenstein é considerado um dos iniciadores da filosofia da linguagem através do Tractatus e das Investigações Filosóficas, mas segundo Saint-Fleur (1998, p. 167) "ele não elaborou nada que se assemelhasse de perto ou de longe ao que poderia ser chamado de tratado de pedagogia" considerando a maneira rapsódia pela qual suas observações são espalhadas aqui e ali em seus dois principais trabalhos e "transcrições de conversas com discípulos ou amigos" (SAINT-FLEUR, 1998, p. 167).

Embora Wittgenstein não tenha elaborado uma teoria em relação à educação, mas suas preocupações filosóficas sobre os conceitos " aprendizado, compreensão, regra, explicação, gramática, significado e significado de um sinal " (SAINT-FLEUR, 1998, p. 168) têm uma grande importância no campo educacional e ajudam os educadores a entender melhor os problemas relacionados à educação e, principalmente, à educação matemática. Especialmente porque a matemática é uma disciplina com uma linguagem simbólica, considerada de acordo com Silveira (2015) como uma língua estrangeira, portanto deve ser traduzida para uma linguagem natural para facilitar a compreensão dos alunos. Além disso, segundo a autora "a matemática é objetivada por meio de sua linguagem, que é regida por uma sintaxe que segue regras matemáticas, 
porém, essa linguagem, quando traduzida para a linguagem natural, passa também a seguir regras gramaticais" (SILVEIRA, 2015, p. 181). Então, a conversão da linguagem natural em linguagem matemática requer que o professor saiba como estabelecer as regras do jogo porque Wittgenstein (1999) deixou claro que qualquer jogo é governado por regras.

Em De la Certitude (1965), Wittgenstein compara a criança a alguém que concede uma fé inabalável a tudo o que o adulto lhe diz com estas palavras: "a criança aprende acreditando no adulto. A dúvida vem depois da crença" (WITTGENSTEIN, 1965, p. 61). Isto mostra o poder dos adultos sobre o comportamento das crianças, então, como possuidores desse poder, os professores têm a sua quota-parte de responsabilidade na tarefa que lhes é atribuída de educar as crianças.

Então, nos primeiros anos da escola, as crianças são receptoras, têm uma memória de ferro e, ao mesmo tempo, são frágeis, será difícil livrarem-se das primeiras aprendizagens. É por isso que os professores devem envidar todos os esforços para fixar o melhor possível as primeiras conquistas das crianças em numeração, adotando um jogo de linguagem baseado na filosofia de Wittgenstein, aplicando as regras que regem este jogo. Antes de entrar na escola pré-primária, algumas crianças já têm uma ideia das ordens de grandezas, elas podem ter a capacidade de distinguir as quantidades 1, 2, em referência às partes de seu corpo, sabendo que elas têm duas mãos, dois pés, uma cabeça... sem os poder quantificar e alguns sabem mesmo recitar sequências de números. Ribière (2006, p. 3) sublinha neste sentido que:

É o ambiente familiar que confronta, pela primeira vez, o jovem com o número. «A aprendizagem da denominação das quantidades começa ao mesmo tempo que a aprendizagem da linguagem. «Um», «dois» aparecem muito cedo. Em contrapartida, a aquisição da sequência de números requer muito mais tempo (Tradução minha).

Neste sentido, o trabalho dos professores nesta fase é preparar estas crianças para a entrada na escola primária porque, segundo Ballieu e al. (2004, p. 5) elas chegam ao jardim de infância com diferentes conquistas que terão de ser enriquecidas e estruturadas. Assim, a criação de uma boa pedagogia adaptada à idade das crianças permita ensiná-las a descobrir os números e a sua utilização, enquanto brincam, refletindo e resolvendo problemas, treinando, lembrando e memorizando. Os objetivos a 
atingir na numeração no final do jardim de infância deveriam permitir à criança avaliar, comparar coleções de objetos, utilizar os números para desenhar a posição de uma pessoa ou de um objeto em relação aos outros, poder comunicar, oralmente ou por escrito, informações sobre uma quantidade, saber que se obtém o número seguinte adicionando 1 ao número precedente, quantificar colecções até pelo menos 10 e saber decompô-las, dizer uma sequência numérica até 30 e ler os números escritos em números até 10 .

$\mathrm{Na}$ escola primária, ensinar de forma adequada a numeração consistiria em primeiro lugar garantir a bagagem linguística da criança em técnicas de contagem, verificar os seus conhecimentos no que se refere à linguagem exigida do sistema de contagem, assim, descobriremos a origem das suas dificuldades. Como Silveira (2015, p. 227) mencionou "é por meio da linguagem do aluno que podemos encontrar a origem de suas confusões e erros, como também, é por meio da linguagem que podemos the ensinar a traduzir corretamente um texto matemático para que o texto Ihe forneça sentido". Procurar onde reside a incompreensão dos alunos é o papel dos professores, e isso vai ajudá-los muito em como fazer para ensinar as regras da linguagem que correspondem às exigências dos sistemas oral e escrito da numeração.

Os numerosos erros das crianças em contagem resultam, por vezes, de problemas de incompreensão, de esquecimento ou da pedagogia de ensino adotada inicialmente que não corresponde às exigências da aprendizagem dos números. A implementação de técnicas que permitam à criança dominar as regras da numeração envolve um jogo de linguagem que guiará passo a passo o aprendizado da criança. No início da aprendizagem dos números a um dígito, o professor deve empregar um vocabulário preciso a fim de permitir à criança diferenciar os termos "algarismo e número", em primeiro lugar, deve saber que um algarismo é um carácter utilizado para representar um número, enquanto um número exprime um valor que pode representar grandezas, quantidades, posições, etc. é representado por um ou mais algarismos.

Para estabelecer as regras da contagem decimal, é necessário proceder por diferentes etapas. Inicialmente, é preciso começar por ensinar às crianças os dez sinais que formam todos os números da nossa contagem decimal. Antes de tudo, é preciso que 
saiba distingui-los tanto no oral como no escrito, utilizando o jogo de linguagem relativo aos números naturais que facilitará a compreensão da criança e mostrá-la a técnica a seguir para escrever esta série de sinais de 0 a 9 que representa unidades simples. De acordo com Wittgenstein (1999), não conseguirá fazê-lo sozinho nem com as suas conquistas anteriores, mas com a ajuda do professor que deve desempenhar plenamente o seu papel de auxiliar escrevendo estes números à frente da criança, ensinar-Ihe as técnicas de adjudicação de um número para outro até que consiga dominar as regras que lhe permitem passar de um número para outro.

Wittgenstein (1999) atribui grande importância à prática e, no ensino, podemos ver que nada funcionará sem treinamento, caso contrário, como faríamos professores para garantir que a criança entenda as regras aprendidas. É só chamar a atenção para o fato de que a criança só será capaz de dominar as regras de numeração na prática, saber como passar de 1 para 2, de uma fatia para outra, para escrever os números em algarismos, escrevê-los em letras, etc. exigem todo um processo, especialmente em francês, com suas áreas de irregularidades que não são fáceis de dominar.

Portanto, o professor deve ser paciente no ato de ensinar, apenas uma vez não será suficiente para a criança dominar uma técnica, nesse caso, é necessário prosseguir com exercícios repetitivos, pois para o Wittgenstein (1999), o domínio de um jogo de linguagem só pode ser feito na prática, porque na primeira vez, certamente haverá erros e para corrigi-los, é necessário repetir, às vezes continuar onde a criança está bloqueada ou às vezes retomar todo o processo, é neste sentido que Wittgenstein (1965, p. § 139) é muito claro quando sublinha que: " para estabelecer uma prática, as regras não são suficientes, são também necessários exemplos. As nossas regras deixam escapatórias e a prática deve falar por si mesma".

A segunda etapa consistiria na passagem dos números para dois, três, quatro algarismos... e é aqui que intervêm os dois aspectos da numeração: decimal e posicional, e foi a partir destes dois aspectos que traçámos as dificuldades dos alunos e gostaríamos de thes comunicar algumas soluções. A transição dos números de 1 para 2, 3, 4... algarismos envolvem outros jogos de linguagem que requerem a aplicação de outras regras para facilitar a compreensão dos novos conceitos, isto exige que o professor 
http://dx.doi.org/10.5965/2357724X07142019094

domine perfeitamente 0 vocabulário que corresponde a esta transição, como Wittgenstein (1965, p. 43) deixou bem claro: "se os jogos de linguagem mudam, mudam os conceitos e, com os conceitos, os significados das palavras". As crianças devem ser lembradas de que a mudança para uma unidade superior, como elas já aprenderam com os dez primeiros dígitos, requer o aumento de uma unidade, então 9 unidades +1 unidade $=10$ unidades $=1$ dezena, colocado assim no quadro:

Tabela da numeração ${ }^{6}$

\begin{tabular}{|c|c|c|}
\hline Centena & Dezena & Unidade \\
\hline & 1 & 0 \\
\hline
\end{tabular}

Desde então, deve-se fazer intervir o quadro de numeração, que é um instrumento muito importante que permite mostrar às crianças, em primeiro lugar, que zero indica a ausência de agrupamento de uma certa ordem, e, em segundo lugar, observar que o valor de um algarismo depende de sua posição na escrita de um número, para que elas não confundam 31 e 13, 15 e 51, 57 e $75 \ldots$

Desenvolver atividades que permitam às crianças superar as suas dificuldades, ao nível de dezenas, utilizando todos os materiais de base 10 possíveis a fim de lhes mostrar que para cada grupo de dezenas $(10,20,30, \ldots)$, a passagem para a dezena superior, requer o último número do agrupamento anterior adicionado de uma unidade, assim para ter 20,30, ., 90, fara-se: 19 unidades +1 unidade $=20$ unidades $=2$ dezenas; 29 unidades +1 unidade $=30$ unidades $=3$ dezenas, $\ldots, 89$ unidades +1 unidade $=90$ unidades $=9$ dezenas e assim por diante.

Wittgenstein sublinha que:

A regra pode ser um auxílio no ensino do jogo. É comunicada àquele que aprende e sua aplicação é exercitada. Ou é uma ferramenta do próprio jogo. Ou uma regra não encontra emprego nem no ensino nem no próprio jogo, nem está indicada num catálogo das regras. Aprende-se o jogo observando como os outros jogam. Mas dizemos que se joga segundo esta ou aquela regra, porque um observador pode ler essas regras nas práxis do jogo, como uma lei natural que as jogadas seguem (WITTGENSTEIN, 1999, p. § 54).

\footnotetext{
${ }^{6}$ Fonte: a autora
} 
http://dx.doi.org/10.5965/2357724X07142019094

É claro que, quando estabelecemos as regras que regem um jogo, torna-se mais fácil compreender e prosseguir este jogo. Como o nosso sistema de numeração oral apresenta zonas de irregularidades em termos de palavras-números inferiores a 100, isso provoca obstáculos na escrita quantificada sobretudo na língua francesa, O que se ouve não coincide com o que se escreve, estas irregularidades situam-se entre 11 e 16 e 70 a 99. Seria bom, numa primeira fase, fazer dominar no oral e na escrita, os números do primeiro grupo (11 a 16) que não apresentam dificuldades maiores de memorização, faça as crianças perceberem que os números de 11 a 16 são formados dos números 1 a 6 e que alguns começam com as mesmas letras (dois e doze, três e treze, quatro e quatorze, seis e dezesseis).

Mas o segundo grupo (70 a 99) merece ser abordado de forma diferente, para que os alunos dominem uma técnica que Ihes permita escrever estes números. Procede-se repetindo os números que formam estes números, para que qualquer confusão seja afastada, para que a criança não escreva: "70" (60 10) , "80" (4 20), "95"(4 20 15) porque elas veem literalmente e ouvem "sessenta-dez", "quatro-vinte" e quatro-vinte-quinze". Para atenuar as confusões da criança, devemos primeiro mostrar a ela os números ocultos por trás desses números e que ela não deve levar em consideração escrevendoos em números.

Para Wittgenstein (1999), o ato de aprender é um jogo de linguagem que facilita a descoberta de outros jogos de linguagem. Assim, outros vocabulários aparecerão com o aparecimento de dezenas, centenas, milhares, milhões, bilhões... que exigem a aplicação de outras regras de contagem decimal. Assim, com a ajuda das técnicas adquiridas anteriormente, a criança não terá dificuldade em compreender a passagem para a centena, 99 unidades +1 unidade $=100$ unidades $=10$ dezenas $=1$ centena. $\mathrm{A}$ atenção da criança deve ser dada ao facto de que um agrupamento de números de três dígitos forma uma classe e esta primeira classe é a das unidades simples.

O ensino dos grandes números vai fazer intervir outros jogos de linguagens e outras regras a seguir. Por exemplo, para os milhares, milhões e bilhões, as crianças descobrirão por meio das atividades que cada um constitui uma outra classe com um agrupamento de três dígitos também e providos de outras peculiaridades na leitura dos números. Elas aprenderão que para ler um grande número (4 053 - 13325 - 146076 - 
227320 130), elas devem primeiro entender "o nome das diferentes classes como separador e não como item" (RIBIĖRE, 2006, p. 39), além de outras técnicas como: a leitura de um grande número faz-se convencionalmente da esquerda para a direita depois de ter organizado os números em grupos de três a partir da direita, ainda se põe dois dígitos depois de cem, três após mil, seis após milhões, etc. e a tónica deve ser colocada na denominação de um número quando ocupa uma determinada posição.

Por último, o estabelecimento de boas técnicas de leitura e de escrita dos números naturais no início da aprendizagem, a utilização prática da linguagem relativa à numeração decimal permitirá à criança dominar e apreender outros tipos de jogos que favoreçam a sua habilidade nas técnicas operatórias, porque a compreensão do sistema de numeração decimal facilitará o seu início no cálculo.

\section{Considerações finais}

Em busca do objetivo de relacionar os jogos de linguagem de Wittgenstein como ferramenta para a compreensão dos meandros das linguagens envolvidas no ensino do sistema de numeração (língua francesa e linguagem matemática) para crianças do nível primário, tomamos consciência da magnitude do problema com a ajuda dos estudos que pudemos analisar.

Dada a importância dos números na aprendizagem escolar, seu ensino não deve ser menosprezado, porque eles intervêm em todos os ramos de atividade e estão na origem de todos as outras partes da matemática.

Ao longo do estudo, descobrimos que as crianças enfrentam dificuldades relacionadas aos aspectos verbais, escritos e posicionais da numeração. A não correspondência do código numérico com o código oral de certos números causa grandes dificuldades na aprendizagem dos números sobretudo na língua francesa porque a numeração oral apresenta zonas de irregularidades e, além disso, ela está na origem do problema das crianças na maneira de posicionar os números.

Moretti (1999, p. 27) sublinha que: "o entendimento do funcionamento dos sistemas de numeração é fundamental na compreensão dos algoritmos e mesmo na 
http://dx.doi.org/10.5965/2357724X07142019094

realização das operações básicas". E diante dos obstáculos enfrentados pelos alunos em numeração, decidimos confiar na filosofia de Wittgenstein, através da qual desenvolvemos as etapas que levam em conta as regras que devem ser usadas para ajudar a criança a fazer bom uso dos jogos de linguagem que lhe permitem dominar os conceitos numéricos.

\section{Referências}

BALLIEU, Michel e al. Pour une culture mathématique accessible à tous: Elaboration d'outils pédagogiques pour développer des compétences citoyennes. Recherche no 100/03 financée par le Ministère de la Communauté Française, Administration générale de l'Enseignement et de la Recherche scientifique, 2004. Disponível em:

http://www.enseignement.be/index.php?page=25074. Acesso em: setembro 2019.

MORETTI, Méricles Thadeu. Dos sistemas de numeração às operações básicas com números naturais. - Florianápolis: Ed. da UFSC, 1999.

PINEL, Nicolas. La difficulté en mathématiques au cycle 2 Animation Pédagogique - CPC EPS, Mission Maths 76, 2015. Disponível em: nicolas.pinel@ac-rouen.fr. Acesso em: setembro 2019

RIBIERE, Thomas. Comment dépasser les difficultés des élèves de cycle 2 et de cycle 3 qui ne parviennent pas à s'approprier notre numération décimale ? 2006

SANTOS, Ivanaldo. Wittgenstein e a importância dos jogos de linguagem na educação infantil. Educação e Linguagem. 2011. Número 17. P. 160-167Jan.-jun. 2008

SILVEIRA, M, R. A. da. Matemática, discurso e linguagens: contribuições para educação matemática. São Paulo: Editora Livraria da Física, 2015.

TEMPIER, Frédérick. La numération décimale l'école primaire. Une ingénierie didactique pour le développement d'une ressource. Éducation. Université Paris-Diderot - Paris VII, 2013.

WITTGENSTEIN. L. Recherches Philosophiques. Éditions Gallimard, 1999.

WITTGENSTEIN. L. De la certitude. Edition française, Gallimard, les essais, 1965. 